\title{
Clinical MEG Analyses for Children with Intractable Epilepsy
}

\author{
Ayako Ochi, Cristina Y. Go and Hiroshi Otsubo \\ Division of Neurology, The Hospital for Sick Children \\ Canada
}

\section{Introduction}

Epilepsy is a brain disorder characterized by recurrent and unpredictable interruptions of normal brain function, called epileptic seizures (Fisher et al., 2005). Epilepsy occurs in 1-2\% of children (Hauser \& Kurland, 1975). Twenty-five percent of children with epilepsy continue to seize despite appropriate medical management and are diagnosed as medically refractory epilepsy (Hauser, 1993). Medically refractory epilepsy is defined as seizures that continue despite at least two appropriate first line anti-epileptic medications at maximally tolerated serum levels for 2 years (Snead, 2001). A subset of patients with medically refractory epilepsy can be surgically treated after anti-epileptic medications fail. Successful control of the seizures can be achieved in children with intractable partial epilepsy by surgical resection of the epileptogenic foci (Duchowny 1995; Wyllie 1998; Snead 2001).

In our institution, magnetoencephalography (MEG) is an essential part of the diagnostic workup in all patients undergoing presurgical evaluation. We introduced the concept of MEG-guided epilepsy surgery (Minassian et el., 1999; Otsubo et al., 1999, 2001a, 2001b; Holowka et al., 2004; Iida et al., 2005; RamachandranNair et al., 2007; Mohamed et al., 2007; Ochi et al., 2008). In patients with intractable partial epilepsy, MEG is a powerful tool for presurgical evaluation to predict an epileptogenic zone (Wheless et al., 1999; Pataraia et al., 2004; Paulini et al., 2007). The epileptogenic zone is a region of cortex that can generate epileptic seizures (Rosenow \& Lüders, 2001). By definition, total removal or disconnection of the epileptogenic zone is necessary and sufficient for seizure freedom. In this chapter, we would like to demonstrate our presurgical evaluation, including scalp videoelectroencephalography (EEG) monitoring to capture seizures and interictal epileptiform discharges, and clinical MEG studies and analyses to estimate the epileptogenic zone.

\section{Scalp video-EEG monitoring}

Scalp video-EEG is crucial before MEG analyses. This can be performed over 1 to 5 days using 19 or 25 scalp electrodes placed according to the International 10-20 system (Jasper, 1958). During scalp video-EEG monitoring, seizure semiology, ictal EEG findings and interictal epileptiform discharges are analyzed in detail to determine lateralization and localization of the seizure onset zone and the irritative zone (Rosenow \& Lüders, 2001). 
Detailed analysis of the scalp video-EEG can predict the approximate epileptogenic zone (Wyllie et al., 1993).

The scalp video-EEG recordings in children often show secondary bilateral synchrony, generalized or multifocal interictal discharges (Wyllie et al., 2007). We have to find (1) consistent leading discharges before these spread to the whole brain, (2) predominant lateralization of multiple independent spike foci, and (3) complexity of spike morphology. Irregular polyspikes/spikes with superimposed fast activity are more epileptogenic than sharp waves with simple and stereotyped morphology. The fast activity is one sign of the epileptogenic zone (Kobayashi et al., 2004; Yamazsaki et al., 2008). Predominantly lateralized or localized interictal spikes during REM sleep also suggest the epileptogenic hemisphere (Samalitano et al., 1991; Ochi et al., 2011). When we analyze MEG data, we always compare the scalp video-EEG and MEG to recognize the characteristics of the interictal spikes, seizure onset zone and seizure semiology for the clinical interpretation of the MEG result.

\section{MEG studies and analyses (recording and analysis)}

Interictal MEG recordings are performed in patients taking their regular dosage of antiepileptic drugs (AEDs). Most of the time, we have found the occurrence rate of interictal spikes was dramatically reduced by maximum dosage of AEDs when patients undergo MEG as an out-patient procedure. The night prior to MEG, patients are sleep-deprived to accentuate focal interictal epileptiform discharges by sleep (Veldfuizen et al., 1983). If patients can undergo MEG recording during their admission for scalp video-EEG, increase in interictal epileptiform discharges are noted during MEG study because anti-epileptic medications are usually tapered to capture seizures for the video-EEG analysis. In children who are unable to cooperate, we use total intravenous anesthesia with propofol and remifentanil for their MEG and subsequent MRI studies (Fujimoto et al., 2009).

We use a whole-head gradiometer-based Omega system (151 channels, VSM MedTech Ltd., Port Coquitlam, BC, Canada) in a magnetically shielded room. Simultaneous MEG and scalp EEG recordings are performed for at least 30 minutes consisting of 15 two-minute periods of spontaneous data. The sampling rate for data acquisition is $625 \mathrm{~Hz}$. Scalp EEG is simultaneously recorded from 19 electrodes placed according to the International 10-20 system. Head positions are measured at the beginning and end of each two-minute period. For optimal accuracy of co-registration of MEG dipole sources onto MRI, the data set in which patients move their head more than $5 \mathrm{~mm}$, is discarded and not analyzed. MEG dipole source localization has been reported to present $2-3 \mathrm{~mm}$ error in comparison of somatosensory evoked fields on MEG with intraoperative evoked potentials (Yang et al., 1993). The data with more than $5 \mathrm{~mm}$ head movement may reach $7-8 \mathrm{~mm}$ localization error to estimate the dipole source which can be localized in the neighboring gyrus; thus these sets are discarded.

Table 1 shows the process of our MEG analysis.

\subsection{Detection and selection of MEG spikes}

We visually identify MEG interictal epileptiform discharges - spikes, polyspikes and sharp waves (referred to as spikes) - by reviewing the 151-channel raw MEG wave forms with band pass filter of $10-70 \mathrm{~Hz}$, and cross-reference them with the simultaneous EEG 
recordings (Fig. 1). Low frequency filter is set relatively high $(10 \mathrm{~Hz})$ to reduce diffuse slow waves in children with intractable epilepsy and to obtain high signal to noise ratio (Sugiyama et al., 2009).

\section{Detection and selection of MEG spikes (Fig. 1)}

1) Band pass filter $10-70 \mathrm{~Hz}$

2) Detection of individual MEG spikes with or without simultaneous EEG spikes

3) Placement of a cursor at the earliest spike peak with reasonable magnetic field topography

4) Selection of the spike $>1$ second apart from previous spikes when continuous spikes occur

\section{Calculation of dipole source by single moving dipole analysis}

$100 \mathrm{~ms}$ window (50 msec before and after the cursor, every $1.6 \mathrm{msec}$, total 63 time points) for sampling rate $625 \mathrm{~Hz}$ (Fig. 2)

\section{Selection of dipole sources (Fig. 2)}

Selection of one dipole source from one spike with following criteria

1) Residual error between measured and calculated magnetic field topographies $<30 \%$

2) Dipole moment 50-400 nAm

3) Dipole locations of consecutive 5-6 time points staying within $1 \mathrm{~cm}$ on $x_{-}, y_{-}^{-}, z_{-}$-axes or within one gyrus

4) Stable strength of dipole moment during consecutive 5-6 time points

5) Dipole with reasonable magnetic field topography with tight "sink and source" pattern and minimum background noise

6) Dipole location in gray matter or gray/white matter junction - with the exception of cortical dysplasia/heterotopia

7) Comparison with simultaneous EEG spike -

if dipole location is deep,

A) dipole with no simultaneous EEG spike;

B) dipole before EEG negative peak

\section{Classification of dipoles}

1) Cluster, defined as 6 or more dipoles with $1 \mathrm{~cm}$ or less between adjacent dipoles

2) Scatter, defined as:

A) fewer than 6 dipoles regardless of the distance between dipoles; or

B) dipoles with greater than $1 \mathrm{~cm}$ between dipoles regardless of number of dipoles

Table 1. MEG analyses 
We analyze individual spikes instead of averaged spikes for dipole source localization in order to obtain the extent of possible epileptogenic zone. The spike-averaging methods may result in loss of spatial and temporal information and of details concerning individual spike types (Sato et al., 1991). Spikes superimposed with electrocardiogram (ECG) are excluded for dipole source localization. When polyspikes or repetitive spikes occur (Fig. 1, red cursor), we select the earliest spike peak with reasonable magnetic field topography for dipole source analysis. The zone of the earliest spike and seizure onset zone demonstrate a high correlation that favors a common epileptic generator (Hufnagel et al., 2000). Some interictal spikes can be better visualized by either MEG or EEG, therefore, ideally, selection of interictal spikes should use both methods simultaneously (Iwasaki et al., 2005; Shibasaki et al., 2007). Various technical factors influence MEG and EEG spike detection, including the number of sensors for MEG and the number of channels for EEG, and in particular, the different characteristics of gradiometer vs. magnetometer for MEG. Needless to say, the methods of source analysis and the availability of experts in each institute are very important in the clinical interpretation of MEG data (Shibasaki et al., 2007).

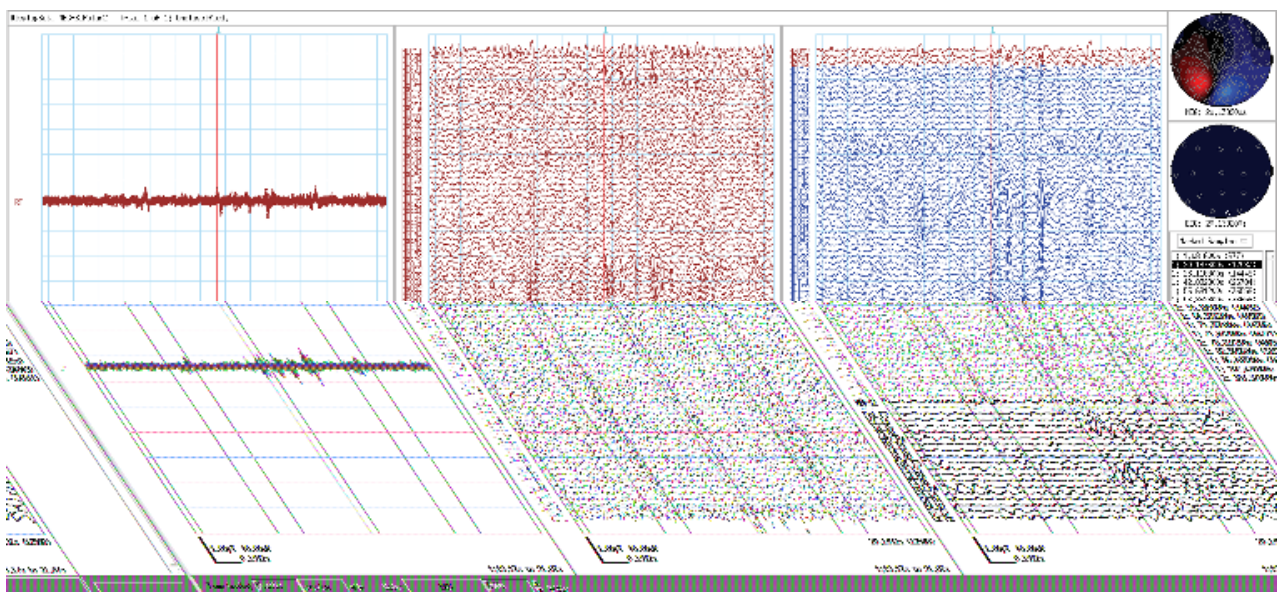

Fig. 1. Detection and selection of MEG spikes. Left panel shows overlaid MEG wave forms over the right hemisphere (brown) and left hemisphere (blue). Middle two panels show raw MEG wave forms of 151 individual coils (right hemisphere, brown; left hemisphere, blue), electrocardiogram (ECG, red) and simultaneous EEG wave forms (black). Right panel shows magnetic field topography (top), EEG field topography (middle), 15 time points of selected spikes during one-set 2-minute recording (bottom). A cursor (red line) is placed at the earliest spike peak in the epoch of four repetitive spikes with magnetic field topography with tight sink and source (top right). Calculation of dipole source is performed $50 \mathrm{msec}$ before and after the cursor (total $100 \mathrm{~ms}$ window, each time point every $1.6 \mathrm{msec}$, total 63 time points).

\subsection{Calculation of dipole source by single moving dipole analysis}

We apply a single moving dipole analysis with a single-shell, whole-head, individuallycreated spherical model. Calculation of the dipole source location, strength and orientation that best fits the measured magnetic fields is performed. For each spike, dipole source solutions are examined every $1.6 \mathrm{msec}$ during a $100 \mathrm{msec}$ window (50 ms before and 50 msec after the peak of spikes, total 63 time points) (Fig. 2). 


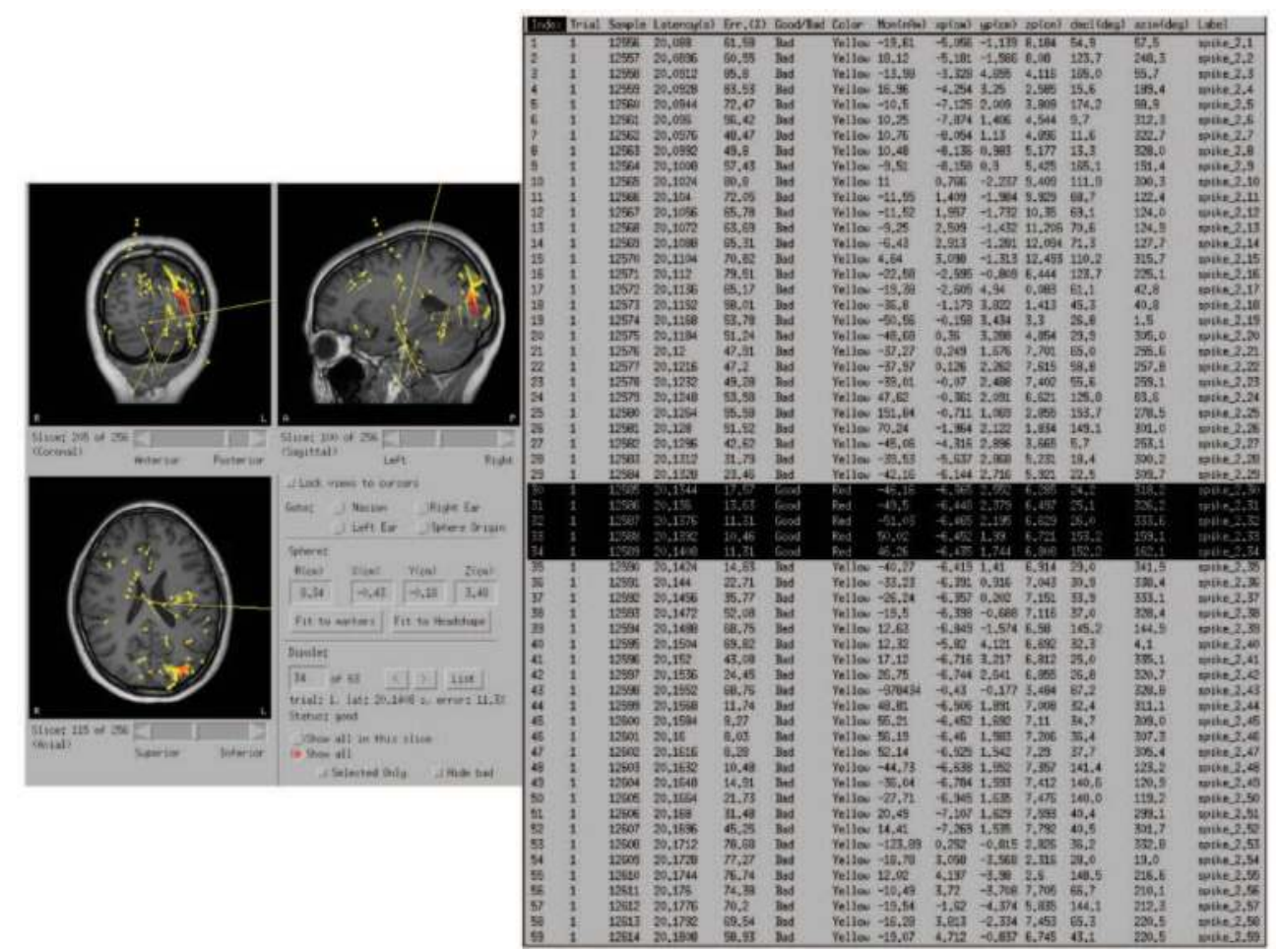

Fig. 2. Stability of dipole locations. Left panel shows coronal (left top), sagittal (right top) and axial MRI. Before selection of MEG dipoles by criteria (Table 1), all calculated MEG dipoles in one dataset (two minutes) are shown on transparent MRI. Right table shows information of all MEG dipoles from one spike before selection by the criteria described in Table 1 (latency, residual error, amplitude, $x-, y-, z$-axes, and angle of moment). To select one dipole from one spike (total 63 time points by sampling rate $625 \mathrm{~Hz}$ ), dipole locations (red circles on MRI) of consecutive 5-6 time points (right, black highlights on the list) stay within $1 \mathrm{~cm}$ on $\mathrm{x}-, \mathrm{y}^{-}, \mathrm{z}$-axes and/or within one gyrus.

\subsection{Selection of dipole sources}

We select one dipole source from each individual spike with the following criteria; (1) residual error $<30 \%$ between measured magnetic field and calculated magnetic field topographies, (2) dipole moment from 50 to $400 \mathrm{nAm}$, (3) dipole locations of consecutive 5-6 time points (4-8ms) staying within $1 \mathrm{~cm}$ on $\mathrm{x}-, \mathrm{y}^{-}, \mathrm{z}$-axes and/or within one gyrus (Fig. 2), (4) stable strength of dipole moment during consecutive 5-6 time points, (5) equivalent current dipole corresponding with tight "sink and source" pattern and minimum background noise on magnetic field topography, (6) dipole source location in gray matter or gray/white matter junction - cortical dysplasia/heterotopia are exceptional (Case 3), (7) Comparison with simultaneous EEG spike - if dipole location is deep, A) dipole with no simultaneous EEG spike or B) dipole before EEG negative peak should be selected.

Our first criterion of residual error $(<30 \%)$ is less strict than that of other institutions because we compare measured and calculated magnetic field topography using whole head 
151 channels and children tend to present with extratemporal lobe epilepsy and/or multiple foci. We try to detect a small disc of cortex at the onset of interictal spike satisfying our criteria (2) to (7). Strict adherence to the above criteria is needed to select the optimal dipole from non-averaged individual spikes and estimate possible epileptogenic zone by MEG dipole source analysis. It also gives us the most consistent results. If we allow too many exceptions to the criteria, distribution of MEG dipoles would be wider than the possible epileptogenic zone, which includes extensive epileptic network such as irritative zone (Rosenow \& Lüders, 2001).

A bundle of pyramidal neuron, which is a small disc of cortex, resembles a dipole source (Gloor, 1985). MEG that was simultaneously recorded with 'intracranial' EEG detected $\geq 3$ $\mathrm{cm}^{2}$ disc of epileptic cortex in the lateral convexity of brain (Oishi et al., 2002). Scalp EEG can detect $10-20 \mathrm{~cm}^{2}$ of gyral cortex in patient with temporal lobe epilepsy (Tao et al., 2005). MEG is superior to conventional 19-channel scalp EEG in detecting the beginning of interictal spike in the fissural cortex (Merlet et al., 1997) because the skull is 'transparent' to the magnetic fields for shallow dipole sources (Okada et al., 1999). After an interictal spike at a small area in the fissural cortex spreads to wider area including crown of gyrus, EEG shows negative peak of the spike after the peak of MEG spike (Merlet et al., 1997). Stability of dipole location and moment suggests focal cortical origin of spikes. When focal cortical origin of spikes quickly shows secondarily bilateral synchrony or becomes generalized, the single moving dipole analysis can be applied only to the 1st leading focal cortical spikes. The 2nd and 3rd spikes during an epoch of generalized spike-and-wave complex involve thalamo-cortical network (Meeren et al., 2002).

\subsection{Classification of dipole sources}

We classify the dipole source locations as follows; (1) A cluster consists of 6 or more dipole sources localized with $1 \mathrm{~cm}$ or less between dipoles; (2) Scattered dipole sources consist of either (A) fewer than 6 dipoles sources, or (B) dipole sources localized more than $1 \mathrm{~cm}$ apart regardless number. (Iida et al., 2005) MEG dipole clusters suggest the epileptogenic zone requires complete excision (Otsubo et al., 1999; Iida et al., 2005).

\section{Case presentations}

We will present MEG analyses in three pediatric cases with intractable partial epilepsy demonstrating 1) polyspikes in Rolandic epilepsy, 2) secondary bilateral synchrony in frontal lobe epilepsy, and 3) deep MEG dipoles without simultaneous EEG spikes in parietal lobe epilepsy.

\subsection{Polyspikes in Rolandic epilepsy}

Pediatric patients with intractable partial epilepsy often present with refractory Rolandic epilepsy that are clinically distinguished from patients with benign Rolandic epilepsy with centro-temporal spikes (Otsubo et al., 2001; Benifla et al., 2009). MEG shows polyspikes in the Rolandic region due to highly epileptogenic focal cortical dysplasia. MEG spike peak appears earlier than EEG spike negative peak in most of cases (Merlet et al., 1997). Especially in cases with the intractable partial epilepsy secondary to the focal cortical dysplasia, MEG dipoles tend to cluster from the earliest spike peak with stable and distinguishable magnetic 
field topography (see Table 1, 1.3, 3.3-5). This subset of focal cortical dysplasia must have dense epileptic neuronal disk to produce a cluster of MEG dipoles.

Case 1 is an almost 13 year old right-handed girl with intractable Rolandic epilepsy. Her seizures started at $6 \frac{1}{2}$ years of age, consisting of nocturnal tonic or generalized tonic clonic seizures, at times associated with enuresis. Scalp video EEG at 12 years of age captured 12 seizures, consisting of right arm jerking from sleep, followed by tonic extension of bilateral arms and right leg. Seizures and interictal epileptiform discharges originated from left centro-parietal region. Three-tesla (3T) MRI showed subtle abnormal signal and blurring of grey/white matter in the left mesial Rolandic region. She was on levetiracetam and phenytoin.

MEG was performed at 12 years of age. The steps from a representative analysis of one spike are shown in Figures 3 to 6.

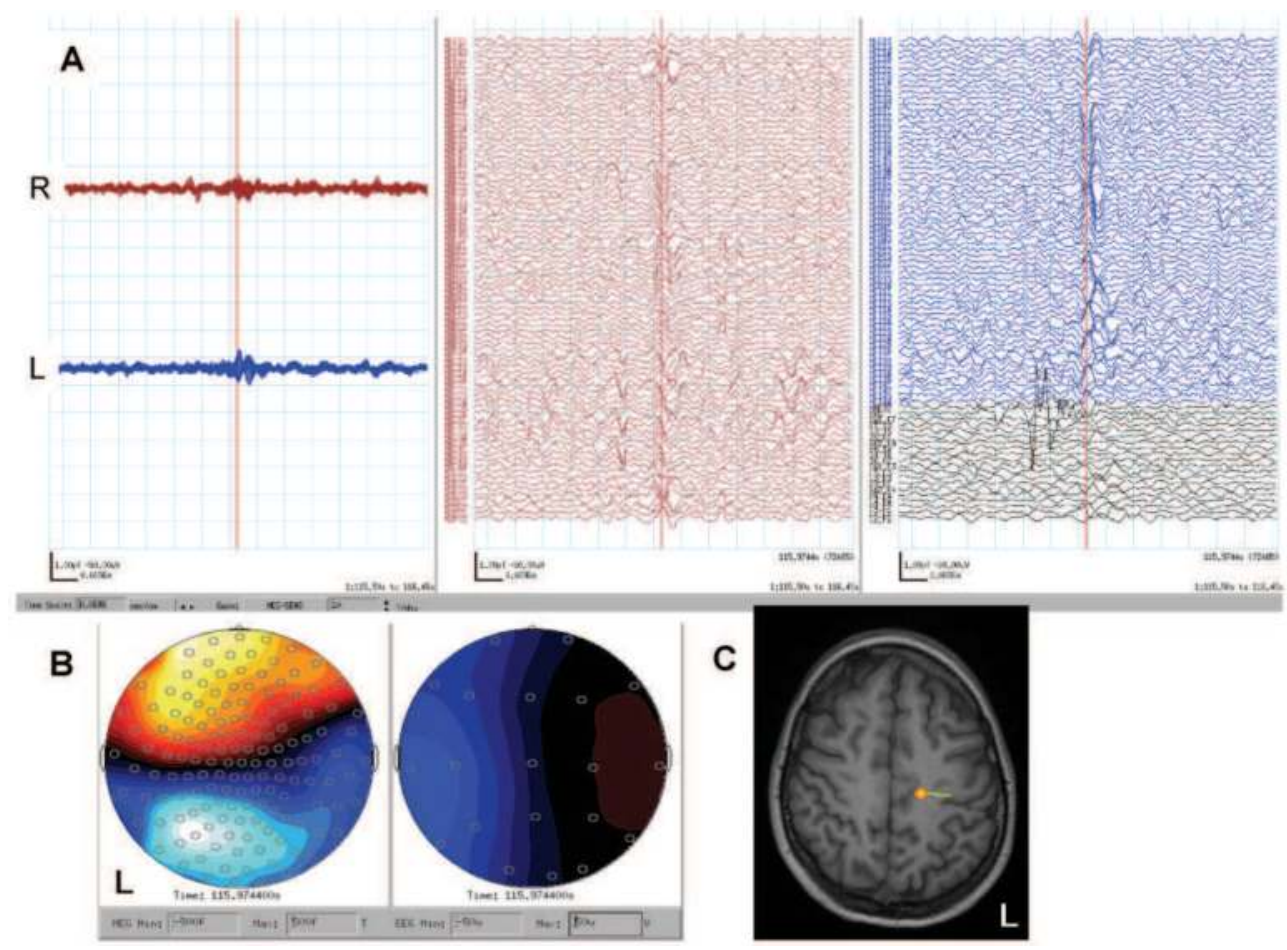

Fig. 3. The first peak of MEG polyspikes. A, MEG shows polyspikes. Left side shows two overlaid wave forms ( $R$, right hemisphere; $L$, left hemisphere) and right side shows individual 151 channels (red channels, right hemisphere; blue channels left hemisphere), ECG and EEG (black channels). The red cursor is placed at the first peak of MEG polyspikes. B, magnetic field topography (left, red is sink, blue is source) and EEG topography (right, blue is positive, red is negative) at the first peak (red cursor on MEG wave forms on A). C, MEG dipole at the first peak of polyspikes is localized beside a subtle MRI abnormality in the left mesial Rolandic region. 


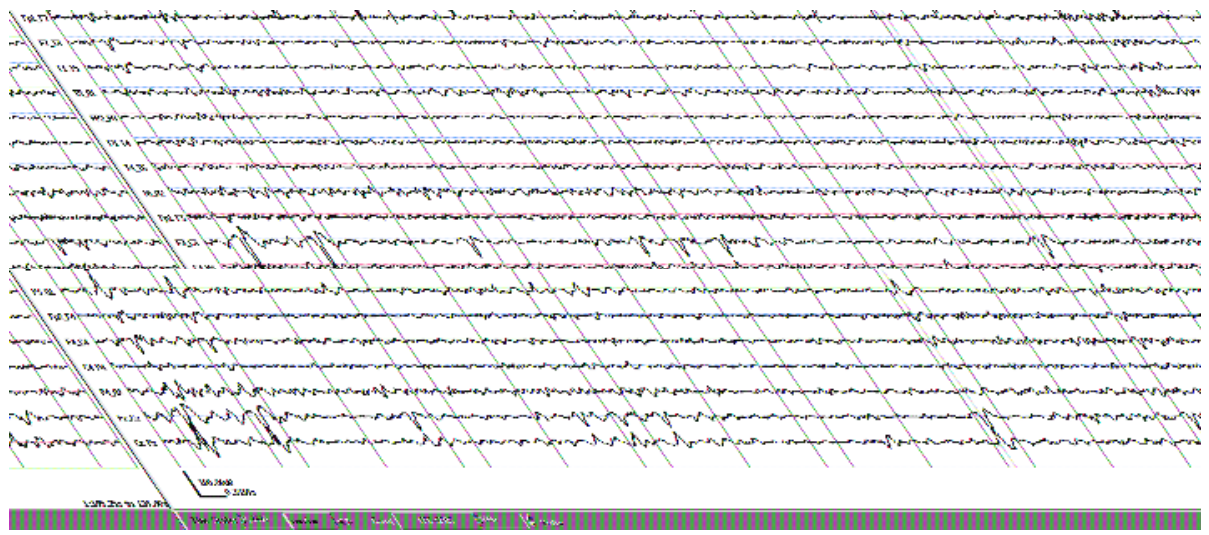

Fig. 4. EEG at the first peak of MEG polyspikes. When MEG shows polyspikes (Fig. 3A), EEG shows simple morphology of spike and wave at C3-P3 and Cz (Fig. 4). The first peak of MEG polyspikes (Fig. 3A, red line) appears before the EEG spike peak (Fig. 4, red line) with 34msec lag.

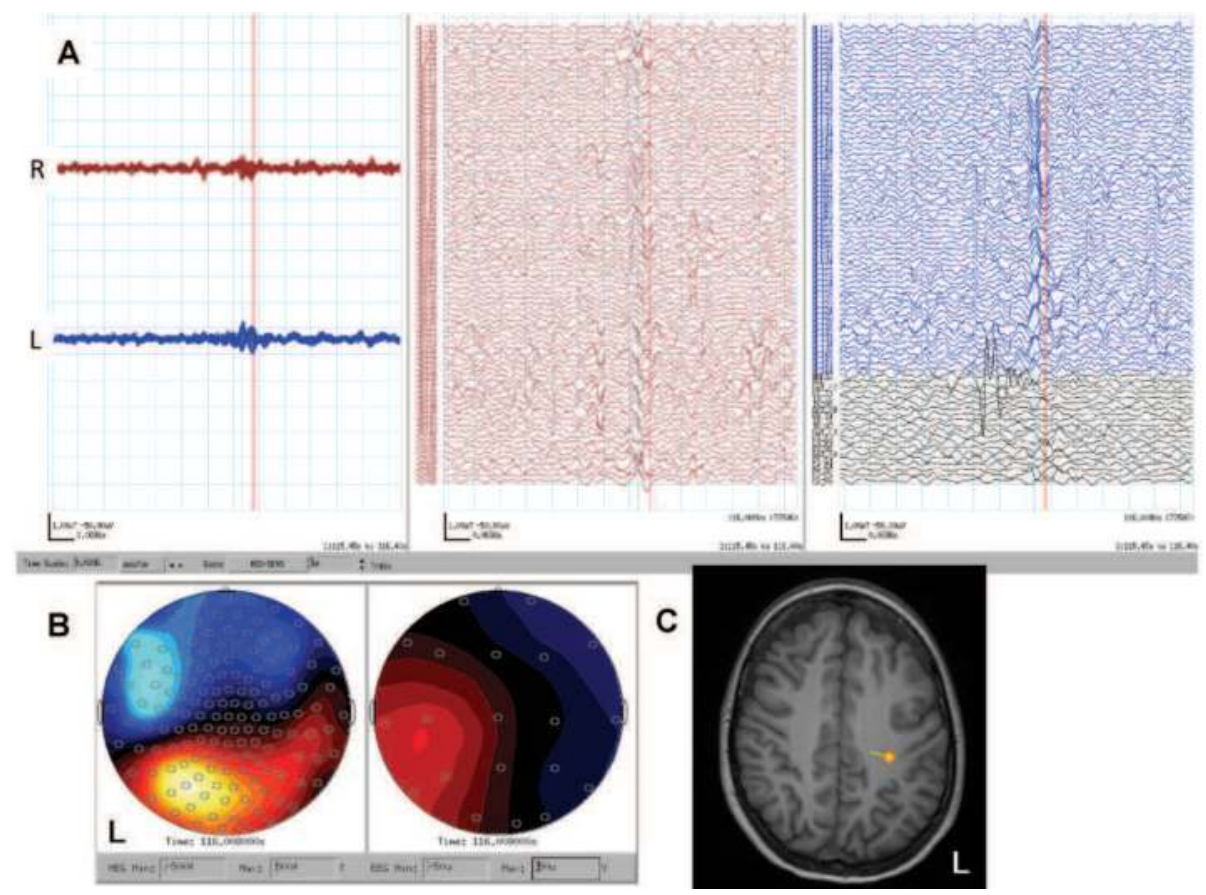

Fig. 5. The second peak of MEG polyspikes. A, MEG shows polyspikes. The red cursor is placed on the EEG spike peak which corresponded to the second peak of the MEG polyspikes. B, magnetic field topography (left) and EEG topography (right) at the EEG spike peak (red cursor on A). C, MEG dipole at the second peak of polyspikes is localized to the left Rolandic region on MRI, lateral to the first peak dipole source (Fig. 3C). It is noted that the dipole orientation and magnetic field topography are in the opposite direction from those of the first dipole (Fig3. C). 


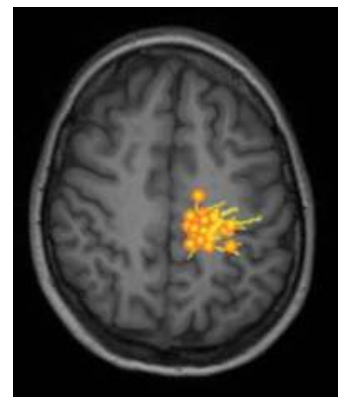

Fig. 6. Cluster of MEG dipoles from one data set. One data set out of 15 two-minute data sets showed a cluster of 26 MEG dipoles fulfilling criteria (see section 3.3) from 43 MEG spikes, which was localized in the left Rolandic region transparently shown on axial MRI.

A total of 203 MEG spikes were detected during 15 two-minute data sets. After dipole calculation from the 203 spikes, 115 MEG dipoles met criteria were selected as the final result. A dense cluster of 109 MEG dipoles was localized in the left mesial to lateral Rolandic region.

Intracranial video-EEG monitoring was performed using subdural grid electrodes over left Rolandic region and depth/strip electrodes toward subtle MRI abnormality in the mesial Rolandic region. Seizure onset zone included both mesial and lateral Rolandic cortices. Mesial Rolandic region started earlier than lateral cortex with a time lag of $300 \mathrm{msec}$ at the beginning of her seizures. Both areas were resected and she has been seizure free for 7 months. She had immediate post-operative right hemiparesis, with almost full recovery of hand and leg motor function 6 weeks after the surgery. Pathology showed focal cortical dysplasia with dysmorphic neurons (type IIa).

\subsection{Secondary bilateral synchrony in frontal lobe epilepsy}

EEGs often show paroxysmal generalized spike-/polyspike-and-wave complexes in children with intractable partial epilepsy even with focal onset seizures (Wyllie et al, 2007). Frontal lobe epilepsy frequently presents with secondarily bilateral synchronized epileptiform discharges (Akiyama et al., 2011). MEG dipoles can be estimated at the earliest peak of spikes before generalization in the spike complex which should have $>1$ sec interval during continuous spike and waves (see Table $1 ; 1.3 \& 1.4$ ).

Case 2 is an almost 17 year old left handed boy with intractable frontal lobe epilepsy. His generalized tonic clonic seizures started at 6 years of age. Scalp video EEG at the age of 16 years captured 16 seizures, consisting of tonic posturing or single jerking of both arms, right arm more than left. Ictal EEG originated from the left fronto-central and temporal regions. Interictal epileptiform discharges consisted of frequent bursts of generalized polyspike-andwaves with left hemispheric predominance and independent focal spikes over the left fronto-central and temporal regions, indicative of secondary bilateral synchrony originating from left hemisphere. 3T MRI showed abnormal signal within subcortical white matter in the left frontal lobe. Functional MRI (fMRI) showed right hemisphere language predominance. He was on clobazam and valproic acid.

A total of 261 MEG spikes were detected. Ninety MEG dipoles were selected as the final result, consisting of 86 in the left hemisphere and four in the right hemisphere. An extensive cluster of 69 MEG dipoles were localized in the left frontal region (Fig. 9). He underwent 


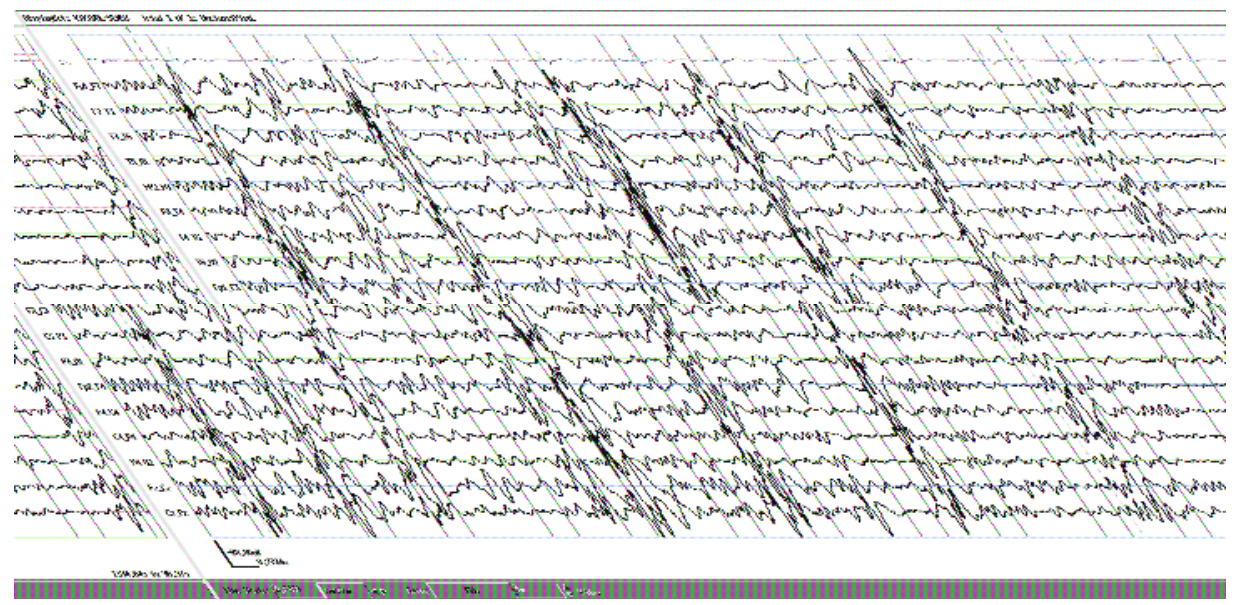

Fig. 7. Frequent generalized polyspike-bursts. EEG shows frequent generalized polyspikebursts. Red cursor is corresponding to the time point in Fig. 8.

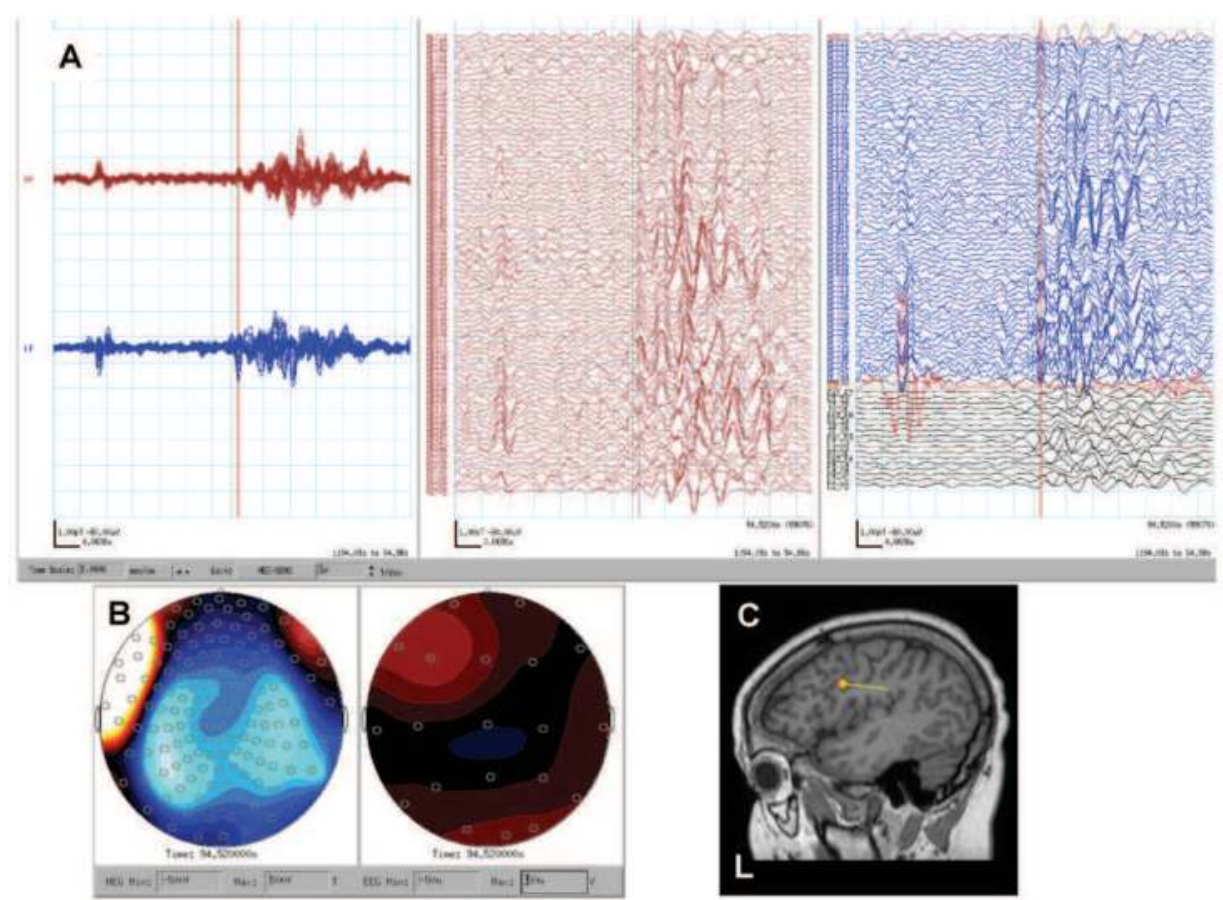

Fig. 8. The earliest component with a reasonable magnetic field topography of generalized polyspike-burst. A, The earliest component with a reasonable magnetic field topography of a polyspike-burst is selected (red cursor). B, Magnetic field topography shows bilateral "sink and source" pattern with left hemispheric predominance. C, Single moving dipole analysis shows an MEG dipole in the left middle frontal gyrus on sagittal MRI. 
intracranial video-EEG monitoring using subdural grid electrodes over the left frontal parietal and superior temporal region and three strip electrodes inserted to left frontal pole and left mesial frontal region. Eight seizures were identical, consisting of single spasm followed by brief tonic seizure of right arm originating from left frontal lobe, superior temporal gyrus and inferior parietal region. Left frontal lobectomy and cortical excision of posterior portion of left frontal lobe, superior temporal gyrus and inferior parietal region were performed. Pathology showed microdysgenesis. He has been seizure free for 11 months.

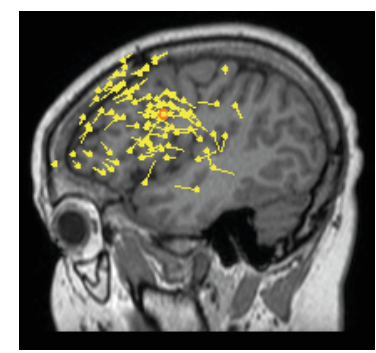

Fig. 9. Total 86 of MEG dipoles in the left hemisphere in Case 2. Sagittal MRI shows a total of 86 MEG dipoles overlaid in the left hemisphere. Sixty-nine dipoles were clustered in the left inferior, middle and superior frontal gyri, anterior to the motor cortex.

\subsection{Deep MEG dipoles without simultaneous EEG spikes in parietal lobe epilepsy}

The epileptogenic focal cortical dysplasia often involves not only the cortex, but also the gray/white matter junction and even the white matter as heterotopia (Blümcke et al., 2011). When a single MEG dipole with large moment is localized in the deep structure in the brain and shows simultaneous high amplitude EEG spike negative peak, the MEG dipole can be falsely localized by the extensive cortical discharges. The single moving dipole analysis for MEG can only be applied well for the "small" disc of cortical discharges, and not the extensive cortical discharges. If MEG dipoles are deeply localized without EEG spikes, the epileptic neurons in the heterotopia truly exist in the white matter (see Table 1; 3.6 \& 3.7).

Case 3 is an 11 year old right-handed boy with intractable partial epilepsy secondary to right temporo-parietal cortical dysplasia. His seizures started at the age of 2.5 years. He was developmentally delayed. His seizures consisted of nocturnal generalized tonic clonic seizures and complex partial seizures (staring, hand and oral automatism). 3T MRI showed abnormally thickened right temporal and parietal cortices, suggestive of cortical dysplasia. Scalp video-EEG at the age of 9 years captured two nocturnal seizures, consisting of tonic clonic seizures with predominant involvement of left arm and face originated from right temporo-parieto-occipital regions. There were frequent interictal epileptiform discharges over the right temporo-parietal regions.

He underwent intracranial video-EEG monitoring using subdural grid electrodes over the right temporal, parietal and occipital region and four depth electrodes inserted to right parietal and right mesial temporal region. Eight seizures started from right temporal parietal occipital regions including subcortical MRI abnormality. Extensive cortical excision of the right parietal including subcortical MRI abnormality, right temporal lobectomy including amygdala and hippocampus were performed. Pathology showed focal cortical dysplasia with neuronal cytomegaly and balloon cells (type IIb). He has been seizure free for three years. 

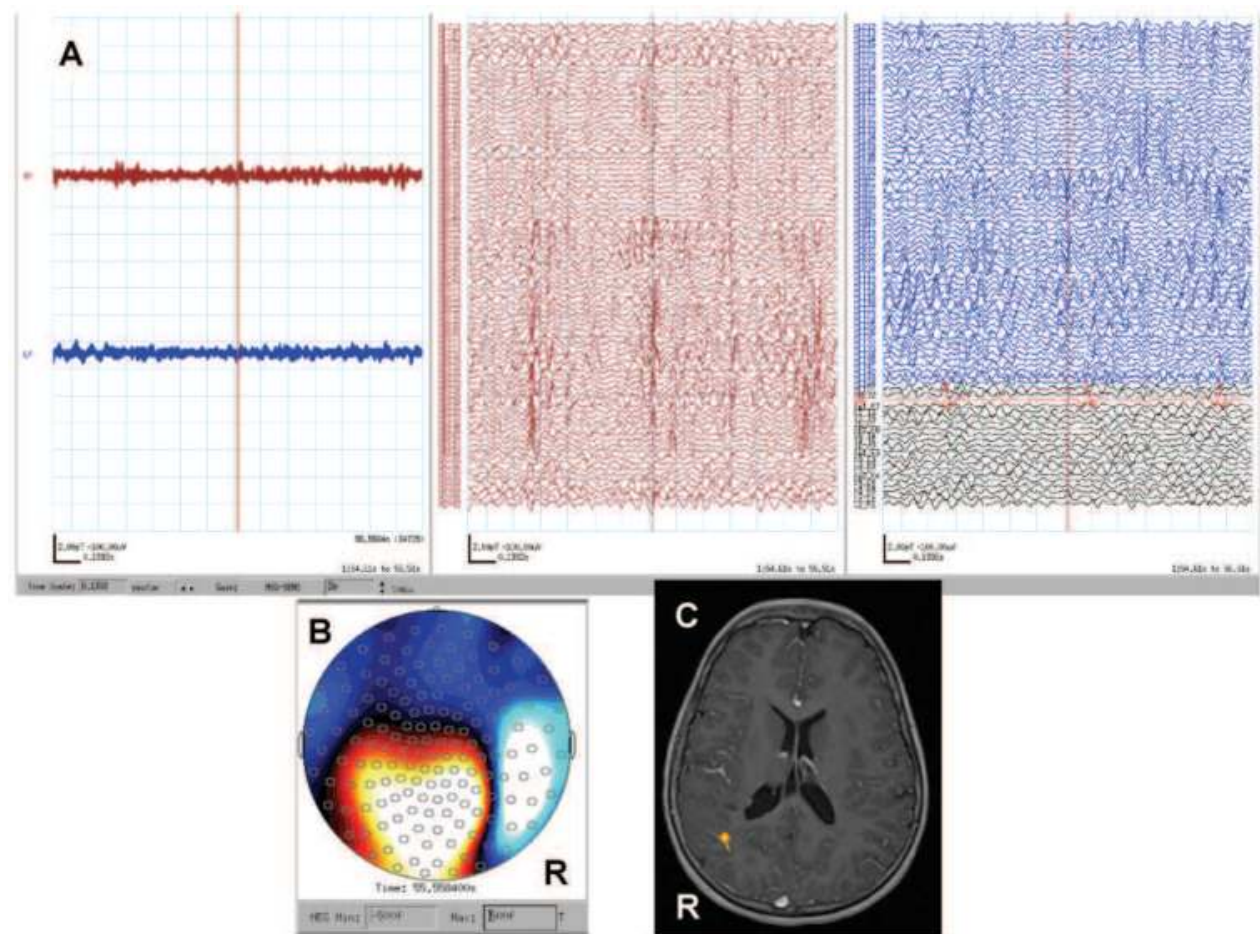

Fig. 10. Deep MEG dipoles without simultaneous EEG spike. A, MEG shows a red cursor at right hemispheric MEG spikes. B, Magnetic field topography shows tight sink and source at the MEG spike peak. C, Single moving dipole analysis shows an MEG dipole in the right temporo-parietal subcortical abnormality on axial MRI.

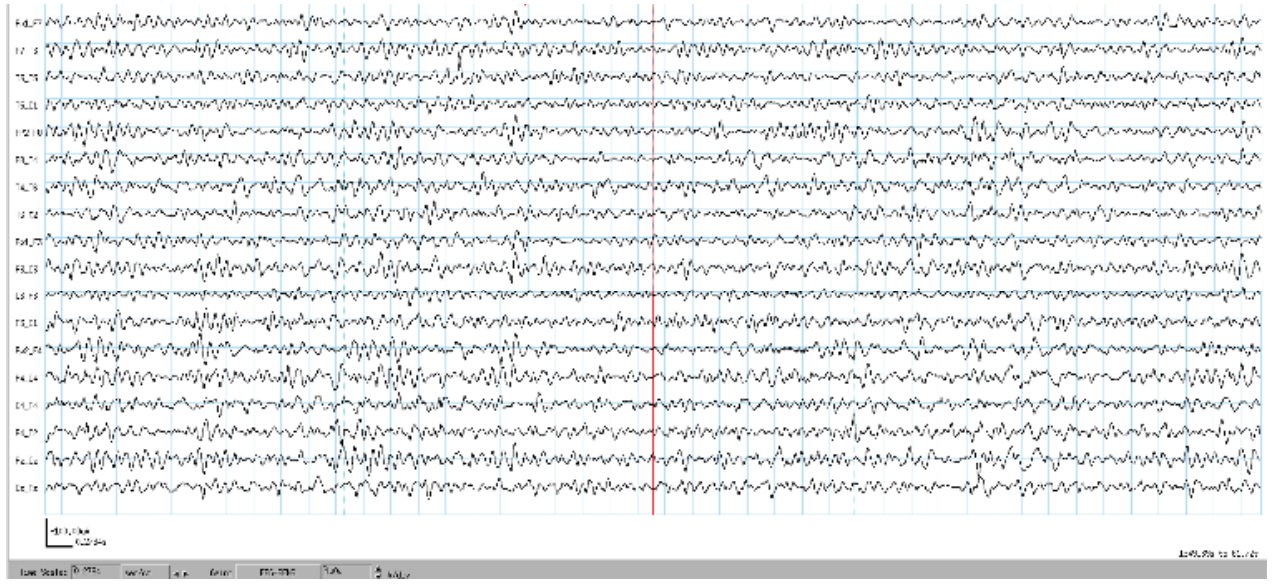

Fig. 11. No spike on simultaneous EEG. There is no spike on EEG (red cursor) while MEG shows right hemispheric spikes (Fig. 10A). 


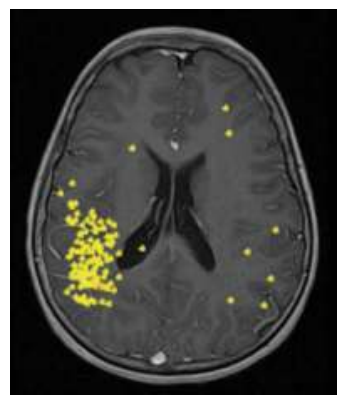

Fig. 12. Total 127 MEG dipoles in Case 3. A total of 127 MEG dipoles are shown on one transparent axial MRI, consisting of 120 over the right hemisphere and 7 in the left hemisphere. Over the right hemisphere, 102 MEG dipoles are clustered in the right temporal and parietal regions. Dipole moments were not shown in this figure.

\section{Conclusion}

We have described analyses of MEG studies as essential tools in the presurgical evaluation in children with intractable partial epilepsy. Our MEG analyses provide high resolution of temporal and spatial information of intracranial epileptic activities for epilepsy surgery. The cluster of interictal MEG dipoles predicts the epileptogenic zone and this is confirmed by intracranial video-EEG monitoring. MEG is indispensable in guiding the surgical treatment of children with medically intractable partial epilepsy.

\section{Acknowledgment}

Our particular thanks to the epilepsy team leader, Dr. O. Carter Snead III, and the neurosurgical team leader, Dr. James T. Rutka. We also want to thank our epilepsy surgery team at SickKids, Mr, Rohit Sharma, Ms. Amrita Viljoen, Mr. Bill Chu, Ms. Stephanie Holowka, Dr. Shelly Weiss, Dr. Elizabeth Donner, Dr. Tomoyuki Akiyama, Dr. Elizabeth Pang, Ms. Irene Elliott, Ms. Christine Jursa, Dr. Elysa Widjaja, Dr. Sylvester H. Chuang, Dr. James Drake, Dr. Mary Lou Smith, Dr. Elizabeth Kerr, Ms. Janice Mulligan; without our strong leaders and excellent team members, this work would not be possible.

\section{References}

Akiyama, T.; Donner, E.J.; Go, C.Y.; Ochi, A.; Snead, O.C. III; Rutka, J.T.; Otsubo, H. (2011). Focal-onset myoclonic seizures and secondary bilateral synchrony. Epilepsy Res, Vol. 95, No. 1-2, pp. 168-72

Benifla, M.; Sala, F. Jr.; Jane, J.; Otsubo, H.; Ochi, A.; Drake, J.; Weiss, S.; Donner, E.; Fujimoto, A.; Holowka, S.; Widjaja, E.; Snead, O.C. III; Smith, M.L.; Tamber, M.S.; Rutka, J.T. (2009). Neurosurgical management of intractable rolandic epilepsy in children: role of resection in eloquent cortex. Clinical article. J Neurosurg Pediatr, Vol. 4, No. 3, pp. 199-216

Blümcke, I.; Thom, M.; Aronica, E.; Armstrong, D.D.; Vinters, H.V.; Palmini, A.; Jacques, T.S.; Avanzini, G.; Barkovich, A.J.; Battaglia, G.; Becker, A.; Cepeda, C.; Cendes, F.; Colombo, N.; Crino, P.; Cross, J.H.; Delalande, O.; Dubeau, F.; Duncan, J.; Guerrini, 
R.; Kahane, P.; Mathern, G.; Najm, I.; Ozkara, C.; Raybaud, C.; Represa, A.; Roper, S.N.; Salamon, N.; Schulze-Bonhage, A.; Tassi, L.; Vezzani, A.; Spreafico, R. (2011). The clinicopathologic spectrum of focal cortical dysplasias: a consensus classification proposed by an ad hoc Task Force of the ILAE Diagnostic Methods Commission. Epilepsia, Vol. 52, No. 1, pp. 158-174

Duchowny, M. (1995). Epilepsy surgery in children. Current Opinion in Neurology, Vol.8, No. 2, pp. 112-116.

Fisher, R.S.; van Emde Boas, W.; Blume, W.; Elger, C.; Genton, P.; Lee, P.; Engel, J.Jr. (2005). Epileptic seizures and epilepsy: definitions proposed by the International League Against Epilepsy (ILAE) and the International Bureau for Epilepsy (IBE). Epilepsia, Vol. 46, No. 4, pp. 470-472

Fujimoto, A.; Ochi, A.; Imai, K.; Chan, D.; Sharma, R.; Viljoen, A.; Chu, B.; Holowka, S.; Kemp, S.M.; Chuang, S.H.; Matsumura, A.; Ayuzawa, S.; Snead, O.C. III; Otsubo, H. (2009). Magnetoencephalography using total intravenous anesthesia in pediatric patients with intractable epilepsy: lesional vs nonlesional epilepsy. Brain Dev, Vol. 31, No. 1, pp. 34-41

Gloor, P. (1985). Neuronal generators and the problem of localization in electroencephalography: application of volume conductor theory to electroencephalography. J Clin Neurophysiol, Vol. 2, No. 4, pp. 327-354

Hauser, W.A. \& Kurland, L.T. (1975). The epidemiology of epilepsy in Rochester, Minnesota, 1935 through 1967. Epilepsia Vo. 16, No. 1, pp. 1-66

Hauser, W.A. (1993). The natural history of seizures. In: The treatment of epilepsy: principles and practices, Wyllie, E. pp. 165-170, Lea \& Febiger, Philadelphia

Hufnagel, A.; Dümpelmann, M.; Zentner, J.; Schijns, O.; Elger CE. (2000). Clinical relevance of quantified intracranial interictal spike activity in presurgical evaluation of epilepsy. Epilepsia, Vol.41, No.4, (April 2000), pp. 467-478

Holowka, S.; Otsubo, H.; Iida, K.; Pang, E.; Sharma, R.; Hunjan, A.; Xiang, J.; Snead, O.C.III.; Chuang, N.; Chuang, S.H.; Rutka, J.T. (2004). Three-dimensionally reconstructed magnetic source imaging and neuronavigation in pediatric epilepsy: Technical note. Neurosurgery, Vol. 55, pp. E1244-E1248

Iida, K.; Otsubo, H.; Matsumoto, Y.; Ochi, A.; Oishi, M.; Holowka, S.; Pang, E.; Elliott, I.; Weiss, S.K.; Chuang, S.H.; Snead, O.C.III.; Rutka, J.T. (2005). Characterizing magnetic spike sources by using magnetoencephalography-guided neuronavigation in epilepsy surgery in pediatric patients. J Neurosurg (Pediatrics 2), Vol. 102, pp. 187-196

Iwasaki, M.; Pestana, E.; Burgess, R.C.; Lüders, H.O.; Shamoto, H.; Nakasato, N. (2005). Detection of epileptiform activity by human interpreters: blinded comparison between electroencephalography and magnetoencephalography. Epilepsia, Vol. 46, No. 1, pp. 59-68

Jasper, H.H. (1958). Report of the committee on methods of clinical examination in electroencephalography: 1957. Electroencephalogr Clin Neurophysiol, Vol. 10, No. 2, pp. 370-375

Kobayashi, K.; Oka, M.; Akiyama, T.; Inoue, T.; Abiru, K.; Ogino, T.; Yoshinaga, H.; Ohtsuka, Y.; Oka, E. (2004). Very fast rhythmic activity on scalp EEG associated with epileptic spasms. Epilepsia, Vol. 45, No. 5, pp. 488-96 
Meeren, H.K.; Pijn, J.P.; Van Luijtelaar, E.L.; Coenen, A.M.; Lopes da Silva, F.H. (2002). Cortical focus drives widespread corticothalamic networks during spontaneous absence seizures in rats. J Neurosci, Vol. 22, No. 4, pp. 1480-1495

Merlet, I.; Paetau, R.; García-Larrea, L.; Uutela, K.; Granström, M.; Mauguière, F. (1997). Apparent asynchrony between interictal electric and magnetic spikes. NeuroReport, Vol. 8, pp. 1071-1076

Minassian, B.A.; Otsubo, H.; Weiss, S.; Elliott, I.; Rutka, J.T.; Snead, O.C.III. (1999). Magnetoencephalographic localization in pediatric epilepsy surgery: Comparison with invasive intracranial electroencephalography. Ann Neurol, Vol. 46, pp. 627-633

Mohamed, I.S.; Otsubo, H.; Ochi, A.; Elliott, I.; Donner, E.J.; Chuang, S.H.; Sharma, R.; Holowka, S.; Rutka, J.T.; Snead, O.C.III. (2007). Utility of magnetoencephalography in the evaluation of recurrent seizures after epilepsy surgery. Epilepsia, Vol. 48, No. 11, pp. 2150-2159

Ochi, A. \& Otsubo, H. (2008). Magnetoencephalography-guided epilepsy surgery for children with intractable focal epilepsy: SickKids experience. Int J of Psychophysiol, Vol. 68, No. 2, pp. 104-110

Ochi, A.; Hung, R.; Weiss, S.; Widjaja, E., To, T.; Nawa, Y.; Shima, T., Go, C.; Akiyama, T.; Donner, E.; Drake, J.; Rutka, J.T.; Snead, O.C. III; Otsubo, H. (2011). Lateralized interictal epileptiform discharges during rapid eye movement sleep correlate with epileptogenic hemisphere in children with intractable epilepsy secondary to tuberous sclerosis complex. Epilepsia, Article first published online: 29 JUL 2011

Oishi, M.; Otsubo, H.; Kameyama, S.; Morota, N.; Masuda, H.; Kitayama, M.; Tanaka, R. (2002). Epileptic spikes: magnetoencephalography versus simultaneous electrocorticography. Epilepsia, Vol. 43, No. 11, pp. 1390-1395

Okada, Y.C.; Lahteenmäki, A.; Xu, C. (1999). Experimental analysis of distortion of magnetoencephalography signals by the skull. Clin Neurophysiol, Vol. 110, pp. 230238

Otsubo, H.; Sharma, R.; Elliott, I.; Holowka, S.; Rutka, J.T.; Snead, O.C.III. (1999). Confirmation of two magnetoencephalographic epileptic foci by invasive monitoring from subdural electrodes in an adolescent with right frontocentral epilepsy. Epilepsia, Vol. 40, pp. 608-613

Otsubo, H.; Chitoku, S.; Ochi, A.; Jay, V.; Rutka, J.T.; Smith, M.L.; Elliott, I.; Snead, O.C.III. (2001a). Malignant rolandic-sylvian epilepsy in children: Diagnosis, treatment, and outcome. Neurology, Vol. 57, pp. 590-596

Otsubo, H.; Ochi, A.; Elliott, I.; Chuang, S.H.; Rutka, J.T.; Jay, V.; Aung, M.; Sobel, D.F.; Snead, O.C.III. (2001b). MEG predicts epileptic zone in lesional extrahippocampal epilepsy: 12 pediatric surgery cases. Epilepsia, Vol. 42, pp. 1523-1530

Pataraia, E.; Simos, P.G.; Castillo, E.M.; Billingsley, R.L.; Sarkari, S.; Wheless, J.W.; Maggio, V.; Maggio, W.; Baumgartner, J.E.; Swank, P.R.; Breier, J.I.; Papanicolaou, A.C. (2004). Does magnetoencephalography add to scalp video-EEG as a diagnostic tool in epilepsy surgery? Neurology, Vol. 62, pp. 943-948

Paulini, A.; Fischer, M.; Rampp, S.; Scheler, G.; Hopfengärtner, R.; Kaltenhäuser, M.; Dörfler, A.; Buchfelder, M.; Stefan, H. (2007). Lobar localization information in epilepsy patients: MEG - a useful tool in routine presurgical diagnosis. Epilepsy Res, Vol. 76, pp. $124-130$ 
RamachandranNair, R.; Otsubo, H.; Shroff, M.M.; Ochi, A.; Weiss, S.K.; Rutka, J.T.; Snead, O.C. III. (2007). MEG predicts outcome following surgery for intractable epilepsy in children with normal or non-focal MRI findings. Epilepsia, Vol. 48, pp. 149-157

Rosenow, F. \& Lüders, H. (2001). Presurgical evaluation of epilepsy. Brain, Vol. 124, pp. 1683-1700

Sammaritano, M.; Gigli, G.L. \& Gotman, J. (1991). Interictal spiking during wakefulness and sleep and the localization of foci in temporal lobe epilepsy. Neurology, Vol. 41, pp. 290-297

Sato, S.; Balish, M. \& Muratore, R. (1991). Principles of Magnetoencephalography. J Clin Neurophysiol, Vol. 8, No. 2, pp. 144-156

Shibasaki, H.; Ikeda, A.; Nagamine, T. (2007). Use of magnetoencephalography in the presurgical evaluation of epilepsy patients. Clin Neurophysiol, Vol. 118, No. 7, pp. $1438-1448$

Snead, O.C.III. (2001). Surgical treatment of medically refractory epilepsy in childhood. Brain Dev, Vol. 23, pp. 199-207

Sugiyama, I.; Imai, K.; Yamaguchi, Y.; Ochi, A.; Akizuki, Y.; Go, C.; Akiyama, T.; Snead, O.C. III; Rutka, J.T.; Drake, J.M.; Widjaja, E.; Chuang, S.H.; Cheyne, D.; Otsubo, H. (2009). Localization of epileptic foci in children with intractable epilepsy secondary to multiple cortical tubers by using synthetic aperture magnetometry kurtosis. $J$ Neurosurg Pediatr, Vol. 4, No. 6, pp. 515-522

Tao, J.X.; Ray, A.; Hawes-Ebersole, S.; Ebersole, J.S. (2005). Intracranial EEG substrates of scalp EEG interictal spikes. Epilepsia, Vol. 46, No. 5, pp. 669-76

Veldhuizen, R.; Binnie, C.D. \& Beintema, D.J. (1983). The effect of sleep deprivation on the EEG in epilepsy. Electroencephalogr Clin Neurophysiol, Vol. 55, pp. 505-512.

Wheless, J.W.; Willmore, L.J.; Breier, J.I.; Kataki, M.; Smith, J.R.; King, D.W.; Meador, K.J.; Park, Y.D.; Loring, D.W.; Clifton, G.L.; Baumgartner, J.; Thomas, A.B.; Constantinou, J.E.C.; Papanicolaou, A.C. (1999). A comparison of magnetoencephalography, MRI, and V-EEG in patients evaluated for epilepsy surgery. Epilepsia, Vol. 40, pp. 931-941

Wyllie, E.; Chee, M.; Granström, M.L.; DelGiudice, E.; Estes, M.; Comair, Y.; Pizzi, M.; Kotagal, P.; Bourgeois, B.; Lüders, H. (1993). Temporal lobe epilepsy in early childhood. Epilepsia, Vol. 34, No. 5, pp. 859-68

Wyllie, E. (1998). Surgical treatment of epilepsy in children. Pediatric Neurology, Vol.19, No.3, pp. 179-188

Wyllie, E.; Lachhwani, D.K.; Gupta, A.; Chirla, A.; Cosmo, G.; Worley, S.; Kotagal, P.; Ruggieri, P.; Bingaman, W.E. (2007). Successful surgery for epilepsy due to early brain lesions despite generalized EEG findings. Neurology, Vol. 69, No. 4, pp. 389-97

Yamazaki, M.; Chan, D.; Tovar-Spinoza, Z.; Go, C.; Imai, K.; Ochi, A.; Chu, B.; Rutka, J.T.; Drake, J.; Widjaja, E.; Matsuura, M.; Snead, O.C. III; Otsubo, H. (2009) Interictal epileptogenic fast oscillations on neonatal and infantile EEGs in hemimegalencephaly. Epilepsy Res, Vol. 83, No. 2-3, pp. 198-206

Yang, T.T.; Gallen, C.C.; Schwartz, B.J.; Bloom, F.E. (1993). Noninvasive somatosensory homunculus mapping in humans by using a large-array biomagnetometer. Proc Natl Acad Sci USA, Vol. 90, Vol. 7, pp. 3098-3102 


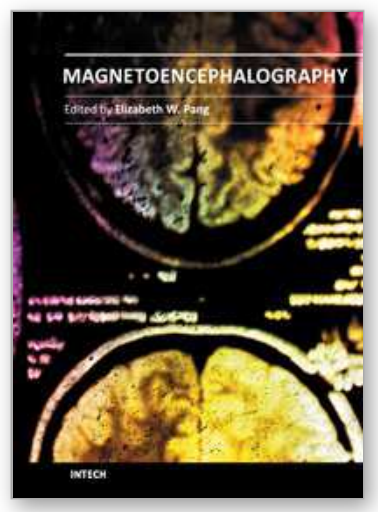

\author{
Magnetoencephalography \\ Edited by Dr. Elizabeth Pang
}

ISBN 978-953-307-255-5

Hard cover, 252 pages

Publisher InTech

Published online 30, November, 2011

Published in print edition November, 2011

This is a practical book on MEG that covers a wide range of topics. The book begins with a series of reviews on the use of MEG for clinical applications, the study of cognitive functions in various diseases, and one chapter focusing specifically on studies of memory with MEG. There are sections with chapters that describe source localization issues, the use of beamformers and dipole source methods, as well as phase-based analyses, and a step-by-step guide to using dipoles for epilepsy spike analyses. The book ends with a section describing new innovations in MEG systems, namely an on-line real-time MEG data acquisition system, novel applications for MEG research, and a proposal for a helium re-circulation system. With such breadth of topics, there will be a chapter that is of interest to every MEG researcher or clinician.

\title{
How to reference
}

In order to correctly reference this scholarly work, feel free to copy and paste the following:

Ayako Ochi, Cristina Y. Go and Hiroshi Otsubo (2011). Clinical MEG Analyses for Children with Intractable Epilepsy, Magnetoencephalography, Dr. Elizabeth Pang (Ed.), ISBN: 978-953-307-255-5, InTech, Available from: http://www.intechopen.com/books/magnetoencephalography/clinical-meg-analyses-for-children-withintractable-epilepsy

\section{INTECH}

open science | open minds

\section{InTech Europe}

University Campus STeP Ri

Slavka Krautzeka 83/A

51000 Rijeka, Croatia

Phone: +385 (51) 770447

Fax: +385 (51) 686166

www.intechopen.com

\section{InTech China}

Unit 405, Office Block, Hotel Equatorial Shanghai

No.65, Yan An Road (West), Shanghai, 200040, China 中国上海市延安西路65号上海国际贵都大饭店办公楼405单元

Phone: +86-21-62489820

Fax: +86-21-62489821 
(C) 2011 The Author(s). Licensee IntechOpen. This is an open access article distributed under the terms of the Creative Commons Attribution 3.0 License, which permits unrestricted use, distribution, and reproduction in any medium, provided the original work is properly cited. 